\title{
CONCEPCIONES CULTURALES, GÉNERO Y MIGRACIÓN ENTRE MAYAS YUCATECOS EN CANCÚN, QUINTANA ROO
}

\author{
Adriana Leona Rosales Mendoza
}

\begin{abstract}
REsumen: Este artículo presenta algunos elementos que contribuyen a mantener la memoria cultural en mayas peninsulares inmigrantes en Cancún, Quintana Roo. Refiero algunas concepciones culturales (rituales, leyendas y concepciones) que permiten a inmigrantes de esta etnia continuar reproduciendo y perpetuando su sentido de pertenencia étnica en ese polo turístico. Los testimonios que se presentan corresponden a cinco entrevistas efectuadas con mujeres procedentes del oriente del estado de Yucatán (X-Can, Temax, Espita, Tunkás, Dzitás, Chemax y Valladolid) durante el proceso de investigación para elaborar mi tesis de doctorado. Las reflexiones para la elaboración de este artículo surgieron en el proceso de dicha investigación y en observaciones de campo posteriores, en las cuales fue posible profundizar en relatos sobre los rituales de chaa chac y hetz-mek, la leyenda Xtabay, el sentido conferido al corazón, y la denominada "metáfora de los ojos de venado".
\end{abstract}

Abstract: This article presents elements of symbolic discourse that contribute to the maintenance of cultural memory in Peninsular Mayan immigrants to Cancun, Quintana Roo, Mexico. I refer to certain (rituals, legends and conceptions) that allow immigrants of this ethnicity to continue reproducing and perpetuating their sense of being Mayan in Cancun, a city which is a magnet for national and international tourism. The testimonies presented are taken from five interviews carried out with women from the eastern part of Yucatan (X-Can, Temax, Espita, Tunkas, Dzitas, Chemax and Valladolid), carried out during research for my doctoral dissertation. The reflections for this article emerged from this research process and later field observations, in which it was possible to explore further the narratives about the chaa chac and hetz-mek rituals, the Xtabay legend, the meaning placed on the heart and the metaphor I have named "deer eyes".

Palabras Clave: concepciones culturales, género, migración, rituales, Cancún, Quintana Roo.

Kfy words: cultural remains, gender, migration, rituals, Cancun, Quintana Roo.

RECEPCión: 14 de enero de 2008.

ACEPTACIÓn: 29 de mayo de 2008. 



\title{
CONCEPCIONES CULTURALES, GÉNERO Y MIGRACIÓN ENTRE MAYAS YUCATECOS EN CANCÚN, QUINTANA ROO ${ }^{1}$
}

\author{
Adriana Leona Rosales Mendoza \\ Universidad Pedagógica Nacional
}

Los procesos globales evidentemente modifican el sentido de pertenencia maya hoy en día, no así la memoria cultural que sigue viva a pesar de que la pobreza y la falta de oportunidades, acentuadas por la globalización, han provocado que miles de indígenas de los estados de Yucatán, Campeche y el propio Quintana Roo sean expulsados de sus comunidades hacia los llamados polos de desarrollo turístico, entre los que destaca Cancún.

Sabemos que al emigrar, el sentido de pertenencia étnica no se pierde, y que sólo cambia en el intento de adaptación a las nuevas circunstancias. El proceso migratorio contribuye a resignificar no sólo el entramado social, sino también el andamiaje corporal y subjetivo en el cual se sustenta el individuo. Se ha documentado que la migración a un medio urbano por parte de indígenas y mestizos rurales no representa una ruptura con la pertenencia a la colectividad de origen; el vínculo con sus familias, redes sociales, sistemas de cargos y prácticas rituales continúan en la nueva residencia, y las vinculaciones con la comunidad se mantienen, por ejemplo, en la celebración de las fiestas patronales o cuando se requiere mano de obra para la siembra y la cosecha. ${ }^{2}$ Pero no todas las personas reconfiguran su pertenencia étnica con la misma intensidad, pues la construcción y reconstrucción de ésta atraviesa por las relaciones de género y generación; dimensiones en las que todavía hace falta profundizar. ${ }^{3}$

Entre las mujeres entrevistadas para la investigación que da origen a este artículo existen preceptos culturales que continúan desplegando en los lugares a los que inmigraron, en este caso, la ciudad de Cancún. Estas concepciones culturales cruzan por procesos de resignificación en los cuales pervive la permanencia y el cambio.

La migración interna es un fenómeno que incide en distintas esferas de la economía, la política, la sociedad y la cultura, e impacta la estructura familiar y a

\footnotetext{
${ }^{1}$ Agradezco al doctor Mario Humberto Ruz por su papel central en la dirección de la tesis.

${ }^{2}$ Martínez y de la Peña (2004), "Migrantes y comunidades morales: resignificación, etnicidad y redes sociales en Guadalajara", Ciudad, pueblos indigenas y etnicidad, Pablo Yanes, Virginia Molina y Oscar González (coords.), p. 91.

${ }^{3}$ Velasco (2002), "El regreso de la comunidad étnica", El regreso de la comunidad: migración indigena y agentes étnicos. Los mixtecos en la frontera México-Estados Unidos, pp. 255-256.
} 
los individuos, y los vínculos que ellos establecen. La migración entraña arreglos entre los miembros de la familia en función de la búsqueda de soluciones para la supervivencia, mejorar las condiciones de vida, y preservar los valores tanto culturales como materiales. ${ }^{4}$

Con el proceso migratorio se crean situaciones nuevas en las que se entrecruzan prácticas culturales propias con otras originadas en el nuevo lugar de residencia. Estas mudanzas conllevan muchas contradicciones porque las personas deben adaptarse a formas de relación que se ven influidas por distintas pautas culturales, por diferentes estilos de vida, por el acceso al empleo o a otro tipo de trabajo, y por el intercambio de ideas y prácticas.

Cancún se fundó a principios de los años setenta del siglo pasado, cuando el entonces presidente de México, Gustavo Díaz Ordaz, y un grupo de banqueros se dieron a la tarea de planear y consolidar una zona hotelera de gran turismo y un centro urbano que albergara a una población que iría llegando de distintos lugares del país. A partir de entonces la migración afectó notablemente su dinámica poblacional. En 1975, el Municipio Benito Juárez, al cual pertenece Cancún, tenía 8500 habitantes, y tres años después contaba ya con $25000 .^{5}$ En 1986 sobrepasaba los 100 000, y según el censo de 1990 la población era de 176765 habitantes, de los cuales el 78.3\% había nacido en otra entidad. De acuerdo con el Censo de Población y Vivienda 2000, la cifra ascendió a 419815 habitantes. La tasa de crecimiento media anual (1990-2005) de Quintana Roo fue de $4.7 \%,{ }^{6}$ mientras que el Municipio Benito Juárez tuvo una tasa de crecimiento de $6.1 \%$ en el periodo comprendido entre 2000 y 2005 , por lo que se estima que en 2006 contaría con una población de 600000 habitantes, ${ }^{7}$ aunque entre 1980 y 1990 creció a un ritmo mucho más acelerado llegando a $17 \%$, y entre 1990-1995 registró un 10.6\%. ${ }^{8}$

En las décadas de los ochenta y noventa, las amplias regiones eran urbanizadas antes de que la población edificara sus viviendas; en la actualidad la planeación municipal en este rubro ha sido rebasada por el enorme flujo migratorio, por lo que las autoridades se limitan a "limpiar" los terrenos, es decir, a ganar espacio a la selva, cortando árboles, plantas y matorrales, eso sí, advirtiéndoles a los futuros colonos que de no empezar a construir, el terreno les será confiscado. ${ }^{9}$

\footnotetext{
${ }^{4}$ Rosales (2006), "Género, cuerpo y sexualidad. Un estudio diacrónico desde la Antropología Social. Concepciones relativas al género, el cuerpo y la sexualidad en culturas mayas y nahuas prehispánicas y coloniales, y en contextos étnicos minoritarios contemporáneos". Tesis de doctorado en Ciencias Antropológicas, Universidad Autónoma Metropolitana-Iztapalapa, México, p. 213.

${ }^{5}$ Martí (1986), Cancún, fantasía de banqueros. La construcción de una ciudad turística en la selva mexicana. México: Uno más uno, p. 5.

${ }^{6}$ INEGI, Tasa de crecimiento media anual de la población por entidad federativa 1990 a 2005, http:// www.inegi.gob.mx/est/contenidos/espanol/rutinas/ept.asp?t =mpob09\&c=3186 (acceso: 21-07-2006).

7 Plan de gobierno municipal. Proyecto: El municipio y su identidad, en http://www.cancun.gob.mx/ pm municipioentidad1.php (acceso: 21-07-06).

$\overline{8}$ Id.

${ }^{9}$ Rosales, op. cit., p. 208.
} 
La dinámica de crecimiento poblacional de Cancún es acelerada, de hecho tiene una de las tasas más altas de población del país, superada sólo recientemente por Playa del Carmen, también en Quintana Roo, la cual tuvo en 2002 un crecimiento de 10.9 , en contraste con Cancún que alcanzó el mismo año un $5.2 \%$, de acuerdo con datos de CONAPO.$^{10}$ En la ciudad de Cancún conviven personas procedentes de distintas partes del país y de la región, lo que la convierte en una sociedad pluricultural. Entre los inmigrantes indígenas, los mayas peninsulares ocupan un lugar preponderante; provienen en su mayoría del estado de Yucatán, y en menor escala de Campeche y del propio Quintana Roo, ${ }^{11}$ aunque recientemente han empezado a llegar indígenas de otras etnias mayences, por ejemplo, chamulas (dedicados casi cien por ciento al comercio).

La migración maya hacia Cancún está compuesta de hombres jóvenes que retornan periódicamente a sus comunidades, ${ }^{12}$ pero también de manera creciente de mujeres que contribuyen al sostén de sus familias. Los mayas yucatecos consagrados en el medio rural a la incipiente agricultura, la cría de animales, la apicultura, la caza, la producción de cestería, el urdido de hamacas, y la confección de hipiles y bordados, se desempeñan en Cancún en el sector terciario (los varones en hotelería e industria de la construcción), y las mujeres en el servicio doméstico y el comercio ambulante.

No obstante, existen diferencias debidas a la posición socioeconómica; quienes poseen más dinero pueden construir casas de tabique, con pisos de cemento o mosaico, y comprar aparatos electrodomésticos, o ser propietarios de un automóvil o de un camión, mientras que los más pobres van sobreviviendo al día. ${ }^{13}$

En una ciudad como Cancún en donde lo más importante es "ser alguien" a costa, muchas veces, del propio ser (horarios laborales extensos, largas distancias por recorrer para llegar al centro de trabajo, días de descanso que no coinciden con los de familiares y amigos), los mayas y otros indígenas, por ser los más pobres entre los pobres, deben pagar un alto precio por acceder a los supuestos beneficios de la denominada "globalización".

En este polo turístico los mayas ocupan, junto con integrantes de otras etnias, las colonias más marginadas, las cuales ni siquiera poseen un nombre propio, ya que se definen como regiones numeradas del sesenta y tantos en adelante. Los servicios públicos en ellas son deficientes, si bien, cuentan —las más privilegiadas, si se puede decir así- con agua potable, drenaje y energía eléctrica. Las

${ }^{10}$ Consejo Nacional de Población, Desafios demográficos para el desarrollo de Quintana Roo, intervención de la lic. Elena Zúñiga Herrera, secretaria general del Consejo Nacional de Población, 15 de enero de 2005, Cancún, Quintana Roo, en http:/www.x/prensa/2005discurso01.pdf\# search $={ }^{\circ} 22$ ta sa $\% 20$ de $\% 20$ crecimiento $\% 20$ media $\% 20$ de $\% 20$ poblacion $\%$ c $3 \%$ b3n $\% 20$ playa $\% 20$ delcarmen $\% 20$ quintana $\% 20$ roo $\% 22$ p. 6 (acceso: 21-07-2006).

${ }^{11}$ Datos del Instituto Nacional del Federalismo y el Desarrollo Municipal en http:/wwwinafed. gob.mx/wb2/INAFED/INAF_Consulta_en_linea_de_ficha_basica (13-04-2004).

${ }^{12}$ Ruz (2002), "Los mayas peninsulares", Los mayas peninsulares. Un perfil socioeconómico, M.H. Ruz (coord.), p. 29.

${ }^{13}$ Rosales, op. cit., p. 224 
regiones del quinientos en adelante (las más nuevas) son amplias áreas ganadas a la selva, sin piedad, en las cuales los mayas recién llegados conviven con otros marginados sociales en palapas mal construidas, con escuelas precarias (si tienen la fortuna de contar con una) y calles sin pavimentar, en espera de que las bondades de la globalización les permitan algún día gozar de la electricidad para mirar en el televisor realidades distantes de la suya. En estas vastas "regiones" habitan hombres y mujeres mayas con aspiraciones y sueños, que si bien están siendo moldeados por "la cultura moderna", no olvidan sus ancestrales concepciones que les permiten afirmar lo que son y han sido.

\section{Espacios mayas en Cancún}

El proceso de conformación de la identidad étnica es muy complejo, por lo que no intento caracterizarla, planteo sólo un esbozo que permita comprender algunas de las maneras en que los mayas del oriente de Yucatán se identifican a sí mismos como indígenas de esta etnia en este contexto de migración. Existen diferentes indicadores para dar cuenta de la pertenencia étnica; aquí sólo refiero algunos señalados por las informantes, como el uso de un atavío, la expresión oral en maya, el respeto y la añoranza por la tierra, dos rituales, una leyenda, una concepción sobre el corazón, y la que he denominado la "metáfora de los ojos de venado". Cabe advertir que el presente trabajo menciona ciertas concepciones culturales, pero no profundiza de manera exhaustiva sobre la construcción de la identidad étnica.

Lo que pude observar a través de la investigación de campo es que la mayoría de los mayas peninsulares adultos que viven en Cancún siguen expresándose en su idioma materno; las mujeres continúan utilizando el hipil, pero las jóvenes prefieren usar vestimentas occidentales, y en vez de hablar o perfeccionar el maya, estudian inglés porque eso les representa conseguir mejores empleos en la industria del turismo. Esto significa que están variando ciertos referentes en torno a la pertenencia étnica; no es que las jóvenes no se sientan mayas, sino que están experimentando su ser mayas de otro modo.

Una de las informantes y sus hijas entablaron conmigo la siguiente conversación, a propósito del uso del idioma maya y del hipil:

-Sí, ya hasta ahora hablo maya.

- ¿Y sus hijos?

-Pues, este, las primeras sí, como por ejemplo, mi hijo Abraham habla maya, mi otra hija que se llama Deisy también, pero ya las demás ya no, las demás ya no.

- ¿Por qué?

-Pus fijate, todas lo entienden, pero nadie lo habla, ellas entienden. Entonces ellas platicaban con mi suegra, a pesar de que no saben hablar en maya, pero le entendían a mi suegra y mi suegra, que ella habla pura maya, también les entendía a ellas. 
—Y su vestido está muy bonito ¿es un hipil bordado a mano, verdad?

-Es típico, es bordado a mano, se le dice hilo contado, que muchos le dicen punto de cruz, es punto de cruz, pero nosotros los mayas le decimos hilo contado porque aquí tienes que contar las cositas estas que haces. Si le pones una más, ya se echó a perder, por eso le dicen que es hilo contado.

— ¿Y ustedes ya no usan el hipil? [Les preguntó a sus dos hijas jóvenes sentadas junto a nosotras].

- La verdad ni lo uso, yo tengo mi terno, yo tengo mi terno, pero no me gusta (Remedios, maya, Valladolid).

Otra de las mujeres entrevistadas comentó al respecto lo siguiente:

—QQuién usa hipil?

- Mi mamá, mis tías, todas casi; pero aquí mis hijas ya no quieren porque dicen que les da pena [las cursivas son mías], y ya mejor usan otras ropas (...) Pues allá en Chemax habla pura maya (Nelsy, maya, Yucatán).

Tanto el uso del idioma maya como del atavío representan para las jóvenes un estigma, dada la discriminación imperante en el medio urbano de Cancún. Esto afecta también la identidad genérica pues, al parecer, las mujeres se perciben como más coquetas y deseables para los varones si se visten con prendas "modernas". Emerge otra identidad genérica al lucir minifaldas, shorts y "ombligueras", al cortarse y teñirse el cabello, y hablar inglés, pues de esta manera existen condiciones para la seducción y para entrar al "mercado de la competencia matrimonial" con otras mujeres, incluso extranjeras.

Por la influencia de los medios de comunicación, los mayas se sienten "integrados" a la nueva vida citadina. Un slogan que se remonta a los años ochenta, y que presenta en la radio y la televisión a personas provenientes de diversos lugares del país, dice más o menos así: "Yo soy Nelsi y nací en Espita, Yucatán; pero ahora soy orgullosamente cancunense". Como se ve, la permanencia —pues no dejan de sentirse mayas-y el cambio, generan nuevas formas de pertenencia cultural.

Los mayas se adaptan en Cancún a una nueva forma de vida que incluye el trabajo remunerado y la asistencia a la escuela, pero por el sentido de pertenencia étnica subrayan también las diferencias, como es visible en el siguiente relato:

Pero ya luego vinieron para acá y ya no quieren regresar. Mis hijas trabaja acá, limpia en casas, así con señoras. Una ya terminó la secundaria y quiere estudiar, iay!, ¿cómo se llama eso? Computación, así dice. Pero ya no quiero que estudie porque allá van dzules y xuunas (así, que no son mayas) (Nelsy, maya, Yucatán).

Se perciben como tales no porque hablen el idioma indígena, ni porque vistan el atavío tradicional, sino porque se sienten ligados a las actividades y pautas culturales que desarrollaban en sus respectivas comunidades. Una de estas labores importantes es la siembra, la cual no pueden seguir realizando en la ciudad, 
a pesar del profundo respeto que sienten por la tierra y los frutos que ésta les provee.

—Qué es lo que más te gusta de ser maya?

-Pues lo que más me gusta es que siembra allá en la casa. Tengo mis chiles, mis rábanos, calabaza, así o también tenía mis animales, puercos. Acá no puedo porque no hay dónde. Está chico y luego cuando llueve se inunda (...) pero mis hijas ya no quiere ir para el pueblo.

- Y cuando en tu pueblo no llueve por un tiempo, ¿qué hacen?

—Pues va a pedir por agua el h-men, con otros señores (Nelsy, maya, Yucatán).

Se mantiene un gran sentido de pertenencia hacia la comunidad en que nacieron y crecieron, y se respetan y reproducen ciertas pautas culturales. Si bien en Cancún a través de la promoción del turismo se ha banalizado y comercializado lo que se denomina "cultura maya" — pues existen espectáculos de corte hollywoodense dedicados a explotar la danza y los rituales como contenidos folclóricos redituables-, los grupos mayas asentados en Cancún continúan realizando ciertas fiestas religiosas vigentes en su lugar de origen, como la celebración a los reyes magos y otros santos. ${ }^{14}$ En la fiesta del día de reyes todas las mujeres suelen vestir hermosos ternos e hipiles, y la mayoría de los varones llevan el traje a la usanza típica. Ahí, los jóvenes tienen oportunidad, sobre todo durante el baile, de relacionarse, coquetear y, tal vez, encontrar una pareja. Todos ponen muchísimo cuidado en su arreglo personal; los hipiles y los ternos son un símbolo de distinción, pues las mejores bordadoras o aquellas con más recursos económicos — para adquirir uno_- visten atuendos más elaborados y elegantes. La danza es una de las manifestaciones de la memoria cultural de los mayas que sigue presente en esta "aldea global" llamada Cancún. ${ }^{15}$

Por otra parte, los rituales constituyen universos simbólicos que refuerzan la normatividad social, dan legitimidad al orden social establecido y confieren sentido a la división sexual del trabajo. A través de ellos, mujeres y hombres ocupan lugares definidos en y por la comunidad; el ejercicio de los papeles o roles conferidos en un ritual tiene un sentido relevante para la sociedad, ya que si éstos no se desarrollan adecuadamente se pone en juego la pervivencia del todo comunitario. ${ }^{16}$

Este tipo de rituales tiene relación con la posesión de los bienes simbólicos que de acuerdo con Bourdieu:

\footnotetext{
${ }^{14}$ Cabe aclarar que otros grupos étnicos y, en general, la mayoría de los mexicanos, festejan la fiesta de reyes, la cual es una celebración religiosa; sin embargo, la manera en que ésta se lleva a cabo presenta ciertas particularidades entre los mayas migrantes del oriente de Yucatán.

${ }^{15}$ Rosales, op. cit., p. 235.

${ }^{16}$ Hernández (2008), "Rituales y género entre las mujeres mayas de Campeche", Revista Digital Universitaria, vol. 9, núm. 7, 10 de julio 2008. Disponible en: http://www.revista.unam.mx/vol.9/num7/ art49/int 49.htm (consultada: 11 de julio de 2008).
} 
Imponen la subordinación de la reproducción biológica a las necesidades de la reproducción del capital simbólico. En el ciclo de la procreación al igual que en el ciclo agrario, la lógica mítico-ritual privilegia la intervención masculina, siempre caracterizada, con motivo del matrimonio o del principio de las labores, por unos ritos públicos, oficiales y colectivos en detrimento de los periodos de gestación, tanto el de la tierra $[\ldots]$ como de la mujer. ${ }^{17}$

Rituales como el chaa chac han entrado en desuso en el contexto de Cancún; sin embargo, cuando los mayas regresan a sus pueblos siguen participando en ellos, ${ }^{18}$ aunque cada vez menos.

Chaa chac $[. .$.$] los hombres, los puros hombres porque las mujeres no pueden ir, no$ van. Las mujeres no pueden ir, ni las niñas, pero mi marido me platicó, están los sapos [los niños que personifican a los sapos], están las chachalacas. Mi marido, él se va allá, y luego cuando están hablando canta ese h-men, porque así lo dice de ese hombre, h-men, chaa chac (Nicté, maya, Espita, Yucatán).

En dicha ciudad se sigue practicando el hetz-mek, cuyo significado para los mayas remite a la concepción mesoamericana de la dualidad complementaria, según la cual los principios femenino y masculino eran considerados indispensables el uno para el otro, pues conformaban una unidad cósmica y social. ${ }^{19}$ En la búsqueda del equilibrio, la transgresión a la norma afectaba a la sociedad en su conjunto, y de igual forma a los antepasados y a los descendientes. Al caer en abusos, como ser flojo, beber demasiado, incurrir en conductas lujuriosas excesivas, y utilizar afrodisíacos o alucinógenos, con la expresa finalidad de obtener placer, se dañaba no sólo a la persona y la comunidad sino al cosmos en su totalidad. ${ }^{20}$

En el principio de la dualidad complementaria se encuentra la base de la división sexual del trabajo, a partir de la cual se diferencian los papeles realizados por hombres o mujeres. Un espacio privilegiado para entender los significados de la dualidad son las representaciones de las deidades, las cuales influían en los espacios de la vida cotidiana. Por ejemplo, Ix Chebel Yax, la Gran Madre, es una diosa senil y desdentada que se asocia con las labores del telar y del agua, cuya pareja Itzam Ná es el Gran Padre, y se representa como un anciano que lleva en su mano un rociador de cascabeles en señal de su función de fecundador; es también guardián de la agricultura. De esta pareja de deidades primordiales surgieron otras deidades masculinas y femeninas como el Sol y la Luna. ${ }^{21}$

\footnotetext{
${ }^{17}$ Bourdieu (2000), La dominación masculina, p. 63.

${ }^{18}$ Rosales, op. cit., p. 239.

${ }^{19}$ De la Garza (1978), El hombre en el pensamiento religioso náhuatl y maya, pp. 31 y ss.

${ }^{20}$ Quezada (1975), Amor y magia amorosa entre los aztecas. Supervivencia en el México colonial, pp. 46-54; Tarazona (1991), La mujer mesoamericana, pp. 81-92.

${ }^{21}$ Báez-Jorge (1988), Los oficios de las diosas. Dialéctica de la religiosidad popular en los grupos indios de México, pp. 64-66.
} 
El ritual del hetz-mek constituye un espacio simbólico para inducir a los pequeños —de acuerdo con su sexo- al mundo femenino o masculino. La ceremonia es casi igual a la que se desarrolla en las comunidades rurales, aunque recientemente se han incorporado otros implementos, como brindar cuadernos y lápices para inducir a que tanto las mujeres como los hombres asistan a la escuela. $^{22}$

A la niña van a dar aguja en su mano, con una hilera, con una tela, eso va a aprender. Al hombre no; le vas a dar la coa, hacha, su sabucán, su garrafón de agua, su guaraches y su cuaderno y su lápiz eso va a aprender; que aprenda ir en la escuela, también la mujer (cursivas mías). Por ejemplo, agarras así [toma un cuaderno que está en la mesal y le dices: esto vas a aprender cuando vayas en la escuela. Al niño y a la niña, a los dos, y empiezas a dar la vuelta nueve veces de la mesa. Entonces, en medio de la mesa vas a poner, este..., pepita gruesas doradas, buñuelos en la mesa también, y empiezas a dar nueve vueltas a la derecha, nueve vueltas a la izquierda (Nacira, maya, Tunkás).

Por otro lado, algunas otras expresiones culturales como la leyenda de XTabay persisten en la ciudad, y refuerzan determinados papeles, como el de la mujer seductora... aquella que no es ni novia ni esposa, pero que castiga el mal comportamiento del adulterio consumado por los hombres.

La X-Tabay es $[\ldots]$ usted eres hombre y estás enamorado de una mujer, y la mujer sabes como se viste, sabes su forma, y por ejemplo, el hombre viene de un camino de que choque con ella. Te enamoras de ella, te enamoras de ella, y luego no es ella [la mujer amada] es X-Tabay, y te vas a dar cuenta porque no está completos los dedos ni de manos ni de pies, le faltan. Allá te vas a dar cuenta de que no es el mujer que buscas, es el kasap ilum, que dicen. Tiene tres dedos, tiene como el marrano [...] Sólo a los hombres se les aparece la X-Tabay, como la novia que no es. Se aparece con su costura anchota y su rebozo, pero, dice mi abuela, que es culebra, las culebras grandes verdes (ixil, maya, Yucatán).

En una de las múltiples versiones de la leyenda, X-Tabay es hermosa y seductora, y ofrece tanto su buen corazón como su cuerpo a los viajeros; en cambio, Utz-Colel es egoísta y despiadada, siente repugnancia por los pobres y no gusta del placer corporal. El corazón de ambas es distinto, pues mientras X-Tabay es caritativa y benévola, Utz-Colel es mala y tiene la piel verdosa, por lo que se parece a una serpiente venenosa (como la que refiere la mujer del relato anterior). Cuando ambas mueren y son enterradas, de la tumba de X-Tabay surgen unas florecillas aromáticas, la flor de Xtabentún, con la cual se elabora un licor, en cambio de la de Utz-Colel emanan hedores repugnantes. ${ }^{23}$ La primera tiene un "corazón limpio", en tanto que la segunda un "corazón torcido o sucio".

\footnotetext{
${ }^{22}$ Rosales, op. cit., 240.

${ }^{23}$ Martínez (2003), "La leyenda de la flor de Xtabetún", Leyendas de los antiguos mexicanos.
} 
En la tradición oral de los yucatecos, quien más se aparece como espectro es la mujer mala, denominada ahora X-Tabay y no con Utz-Colel; emerge al pie de una ceiba para atraer con sus perfumes y palabras a los hombres; los seduce y los embruja, haciéndose pasar por la amada, pues en su carácter de ánima puede tomar la figura de cualquier mujer. Los hombres, sobre todo los que van al monte a cazar, deben cuidarse de esta tentación. Si el varón no muere en sus brazos, amanecerá con huellas de rasguños o el pecho abierto por unas afiladas garras. ${ }^{24}$

La asociación entre el buen corazón y el gusto por el placer carnal, por un lado, y la actitud egoísta y la continencia sexual, por otro, es peculiar, y se contrapone a la concepción más "globalizada" (marcada por el cristianismo) que concibe un buen corazón como aquel que está libre de los llamados pecados de la carne. Los antiguos nahuas creían que cuando una persona tenía un mal proceder su corazón "se torcía". Los mayas yucatecos de la Colonia concebían que el corazón era el centro de la voluntad, el albedrío, el gusto, la prudencia y la imaginación. Vida de corazón (cux- $a$ ' nol) significa tener juicio o discreción. ${ }^{25}$

Esta concepción del corazón "torcido" continúa vigente entre mayas habitantes de Cancún, y se enuncia en el pensamiento de una mujer al hablar sobre una mala acción desarrollada por una pariente que no fue solidaria con ella ante la muerte de su padre. El corazón "se ensucia" si no se cumple con lo esperado por el grupo, independientemente del sexo de la persona; incluso en el caso de las mujeres los deberes de género van más allá del simple ejercicio de los roles sexuales, es decir, se puede dejar de lavar la ropa, pero no se debe perder el sentido de solidaridad.

Una hermana de mi madrastra de aquí dice "Ay, no me gusta andar con la ropa sucia así". Mira, le digo, dime una cosa, tú te sientes muy católica, de la lglesia católica. Cómo te sientes bien arreglada [si] el corazón lo traes sucio. Yo ando así como lo ves, pero el corazón yo [lo] traigo limpio, es, como te digo, encima sucia, [pero] por dentro está limpia, y tú estás limpia encima y abajo sucia, ¿qué haces?, ¿qué harías?, ¿cómo te sientes? [...] [después que] viste cómo murió mi papá: murió como un perro, y así te va a pasar a ti; pero yo no te abandono (Nicté).

A través del corazón se manifiesta el ser, para bien o para mal, y se revela la "limpieza" o "suciedad" del ser. Vemos cómo se entretejen aquí una concepción de la cultura maya (la idea de un corazón prudente y con voluntad) y la percepción de que para ser católica hay que ser solidaria.

En el maya yucateco de la Colonia existen dos palabras para corazón: puczikal "corazón de animal voluntad, ánimo para obrar" (parece hacer alusión a su condición física) y el término ol, ya mencionado. Los conceptos derivados del último vocablo permiten profundizar en la importancia conferida a esta parte del cuerpo.

\footnotetext{
${ }^{24}$ Rosales, op. cit., p. 250.

${ }^{25}$ De la Garza, op. cit., pp. 71-75.
} 
Por ejemplo, ol-ha "corazonar" quiere decir tener voluntad, albedrío o gusto; cuxa' nol "vida de corazón" expresa juicio, prudencia o discreción; $u$ dzib ol "lo que se pinta en el corazón" significa imaginación o pensamiento; utz ol "corazón bueno" enuncia el afecto con que algo se hace; cux-ol "vida del corazón" formula la idea de ser juicioso, racional, prudente, entendido, y el término chacuxolal "recobrar la vida del corazón" habla de adquirir prudencia o recuperar la razón. ${ }^{26}$

El cuerpo y sus órganos (corazón, hígado, etcétera) constituían para los mayas precolombinos el sustento de la persona. Probablemente otras zonas del cuerpo eran tenidas también como forjadoras del ser humano, aunque al perderse buena parte de los códices mayas mesoamericanos en el auto de fe realizado por fray Diego de Landa, en Maní, durante la Colonia, no se cuenta con datos suficientes para sustentar que los ojos y la mirada humana y de los animales eran cruciales para la conformación de la persona maya. De hecho, los animales juegan un papel relevante en las concepciones de la persona entre los tzotziles de la actualidad; el alma se divide en dos, uno de estos elementos es el llamado wayjel, que es un animal silvestre que funge como intermediario entre el ser humano y la naturaleza, puede ser el búho, el jaguar, el gato montés, el colibrí o el venado, por lo que cada uno está obligado a proteger su wayjel, pues la vida propia depende de la del alma animal. ${ }^{27}$

En las representaciones culturales mayas peninsulares de la actualidad es posible hallar relatos como el que presento a continuación, en donde los ojos de venado aparecen como protagonistas de una historia de seducción que le da forma a la persona configurando su identidad de género.

\section{La metáfora de "los ojos de venado"}

Nicté es una mujer hermosa, ${ }^{28}$ como dicen en Yucatán. Su biografía es peculiar. Emigró a Cancún a los 40 años, ahora tiene $61 .^{29}$ Aprendió español a su llegada a la ciudad. Se percibe a sí misma como una mujer muy atractiva que tiene que poner constantemente a los hombres en su sitio. Se comporta con el garbo característico de las mujeres mayas; actúa con dignidad y con elegancia. Si algo no le gusta te lo dice, si no quiere decir algo, se calla.

Socializada en la cultura maya, decidió probar suerte en otro sitio debido a que su marido estaba enfermo ${ }^{30}$ y no ganaba lo suficiente, motivos por los que él se

\footnotetext{
${ }^{26}$ Ibid., pp. 71-75.

${ }^{27}$ Pitarch (1999), "Almas y cuerpos en la tradición indígena tzeltal", Encuentro de almas y cuerpos entre Europa medieval y mundo mesoamericano, México: Universidad Autónoma de Chiapas, Pedro Pitarch, Jérồme Baschet y Mario Humberto Ruz (coords.), pp. 16-24.

${ }^{28}$ Una mujer hermosa es, de acuerdo con los preceptos culturales, una mujer gorda, aunque no obesa.

${ }^{29}$ Realicé tres entrevistas a Nicté a partir del año 2000, cuando tenía 58 años.

${ }^{30}$ Muchas veces la enfermedad es el alcoholismo.
} 
quedó en su pueblo al cuidado de los hijos pequeños. En total tuvo once hijos, de los cuales sobreviven siete. Cuenta que "su señor" la golpeaba, y que ahora ella le pega, que ya no se deja, dice: “¿y cómo, si yo lo mantengo a él?".

Cuando era pequeña, su padre salía a cazar, y le daba a comer los ojos de los venados que atrapaba, para que cuando ella creciera resultara suficientemente atractiva a los hombres. Mediante este sortilegio llegó a tener múltiples enamorados, que la seguían cuando cruzaba el monte. Su poder de seducción iba creciendo con los años, por lo que le faltan dedos en las manos para contar a sus pretendientes. Según cuenta, en los bailes a los que asistió en su juventud había riñas por su amor entre varones del pueblo y de las cercanías. Sin embargo, como era la costumbre, su padre escuchó la petición de un hombre, no tan joven, que la pidió en matrimonio. Se casaron y tuvieron muchos hijos. Al paso del tiempo ella emigró a Cancún, y desde que llegó comenzó a tener pretendientes "jóvenes y guapos porque mi papi me daba a comer muchos ojos de venado". En su relato se puede apreciar una idea mágica, una bella metáfora sobre el poder que les confiere a los ojos de venado para hacerla seductora y provocar el enamoramiento. Esta peculiaridad de construirse como una mujer seductora, de percibir un poder concedido por un ser de la naturaleza, como es el venado, tiene que ver con elementos culturales específicos de la cultura maya yucateca.

-Dicen que, que cuando uno come los ojos de venado entonces que echa el ojo [...] Cuando ya está cocido yo lo saco el ojo y ya lo como, ansi yo lo como los ojos iCuántos muchachos... todos está enamorado de míl Sí por eso dicen que por eso echa ojo, pos fijate cualquiera que me ve, enseguida se pega el ojo.

Los ojos de venado son buenos para enamorar. Sí, muchos [enamorados] me salen, dicen sí, por los ojos del venado. Pero a veces mi papá me decía ¿y los ojos del venado? Ya los comí papi. Si sigues comiendo muchos ojos de venado, mucho no es bueno, te van a echar ojo muchos, me dice.

- ¿Y ya no comes ojos de venado?

-Ya no, ya no, ya ves, los que tengo que comer ya los comí (risas) (Nicté, maya, Espita, Yucatán).

Ella considera que los ojos de venado que comió en su juventud han sido suficientes para seguir manteniendo su poder de seducción. En la actualidad, a sus casi 62 años, asegura que los hombres la enamoran, chicos de 18,20 o 40, mexicanos, "gringos" y hasta japoneses. Ella no tiene que recurrir al "embrujo" que utilizan otras mujeres para conseguir un hombre, consistente "en cortarle un cabello del bigote o barba para guardarlo debajo del fogón, con la candela encendida, así se pega contigo y no te deja”.

La seducción era considerada por los mesoamericanos como un poder inherente a la persona, que podía aumentarse mediante el uso de ciertos sortilegios de amor. Se utilizaban yerbas, piedras de colores, pajas, flores y plumas de aves, entre otros objetos, para atraer la atención del ser amado. Estas prácticas fueron luego consideradas como brujería por los frailes, quienes mediante el catecismo 
impulsaban un discurso para contener o moderar el erotismo, y en el confesionario reprimían y ordenaban castigos para "contener" los placeres de la carne. En la actualidad, algunas de las concepciones prehispánicas prevalecen, como se pudo apreciar en la leyenda de X-Tabay y en el ejemplo de la metáfora "de los ojos de venado".

En Cancún, al resignificar lo cultural, las jóvenes de ascendencia maya advierten que el poder de provocar el enamoramiento, mediante la seducción, se vincula con elementos más mundanos, como vestir un atuendo "sexy", caminar con movimientos cadenciosos, actuar en forma coqueta y "femenina", o bien, mirar como venado, aunque sólo sea porque tradicionalmente se identifica que contemplar como lo hace este animal es señal de estar enamorado. La concepción mágica del poder de los ojos de venado se traslada al que confiere el uso de un atavío y la utilización de un lenguaje corporal que permite conquistar a un hombre y competir con otras jóvenes. De esta forma, la identidad de género se resignifica y da paso a nuevas formas de experimentar el cuerpo. Es posible observar la pervivencia de una imagen corporal sensual, propia de la cultura maya, contrapuesta a la noción del pecado de la carne, pues cabe destacar que entre las informantes de esta etnia no se hizo alusión a la culpa por cuestiones de índole sexual.

\section{Reflexión final}

Como se ha visto, los rituales del chaa chac y el hetz-mek, la leyenda de X-Tabay, la noción del corazón "limpio" o "sucio" y la "metáfora de los ojos de venado" permiten apreciar la persistencia de ciertas concepciones de la memoria cultural de los mayas yucatecos dentro de las nuevas "aldeas globales". El proceso migratorio no es capaz de aniquilar dicha memoria, aun a pesar de los cambios vertiginosos a los que los mayas se enfrentan en este proceso, en virtud, quién sabe si del anhelo de sumarse a la "modernidad" o del infortunio de haber sido expulsados de sus comunidades rurales por la falta de oportunidades de educación y empleo, así como de inversiones en el campo, a raíz de que se acentuó la política económica neoliberal en los últimos años.

Hombres y mujeres mayas continúan expresando su cultura de múltiples formas, ya sea a través del idioma, las fiestas religiosas o familiares, las leyendas, los rituales, y la historia oral, como la "metáfora de los ojos de venado", la cual si no está anclada en el pasado mesoamericano y colonial, al menos sí lo está en la naturaleza, a la que siguen respetando profundamente, pues de la tierra y su entorno proviene el sustento. Además de que el venado alimenta el cuerpo también es capaz de nutrir el alma, y a través de sus ojos, forjar a la persona y su identidad genérica.

En estas breves líneas espero haber mostrado algunas de las manifestaciones culturales, a través de las cuales los mayas permanecen y perpetúan su memoria en contextos globales como Cancún, que las más de las veces resultan adversos. 


\section{BIBLIOGRAFÍA}

Báez-Jorge, Félix

1988 Los oficios de las diosas. Dialéctica de la religiosidad popular en los grupos indios de México. México: Universidad Veracruzana.

Bourdieu, Pierre

2000 La dominación masculina. España: Anagrama.

Consejo Nacional de Población (CONAPO)

2005 Desafios demográficos para el desarrollo de Quintana Roo, intervención de Elena Zúñiga Herrera, secretaria general del Consejo Nacional de Población, 15 de enero de 2005, Cancún, Quintana Roo, p. 6, http://www.x/prensa/2005 discurso01.pdf\#search $=\% 22$ tasa $\% 20$ de $\% 20$ crecimiento $\% 20$ media $\% 20$ de $\% 20$ poblacion $\% 3 \%$ b3n $\% 20$ playa $\% 20$ delcarmen $\% 20$ quintana $\% 20$ roo $\% 22$ (acceso: 21-07-2006).

De la Garza, Mercedes

1978 El hombre en el pensamiento religioso náhuatl y maya.México: UNAM, IIFL, Centro de Estudios Mayas.

Hernández García, Eulalia

2008 "Rituales y género entre las mujeres mayas de Campeche". México: Revista Digital Universitaria, vol. 9, núm. 7, 10 de julio 2008, http://www.revista. unam.mx/vol.9/num7/art49/int49.htm

INEGI

2006 Tasa de crecimiento media anual de la población por entidad federativa 1990 a 2005, http://www.inegi.gob.mx/est/contenidos/espanol/rutinas/ept.asp?t= mpob09\&c $=3186$

Instituto Nacional del Federalismo y el Desarrollo Municipal (INAFED)

2004 Ficha básica, http://www.inafed.gob.mx/wb2/INAFED/INAF

Martí, Fernando

1986 Cancún, fantasía de banqueros. La construcción de una ciudad turística en la selva mexicana. México: Uno más uno, p. 5.

Martínez, Regina y Guillermo de la Peña

2004 "Migrantes y comunidades morales: resignificación, etnicidad y redes sociales en Guadalajara", Ciudad, pueblos indigenas y etnicidad, p. 91, Pablo Yanes, Virginia Molina y Oscar González (coords.). México: Universidad de la Ciudad de México, Gobierno del Distrito Federal.

Martínez, Susana

2003 "La leyenda de la flor de Xtabetún", Leyendas de los antiguos mexicanos", pp. 43-46. México: Editores Mexicanos Unidos. 
Pitarch, Pedro

1999 "Almas y cuerpo en una tradición indígena tzeltal", Encuentro de almas y cuerpos entre Europa medieval y mundo mesoamericano, pp. 15-40, Pedro Pitarch, Jérôme Baschet y Mario Humberto Ruz (coords.). México: Universidad Autónoma de Chiapas.

Plan de Gobierno Municipal. Proyecto El municipio y su identidad

2007 http://www.cancun.gob.mx/pm_municipioentidad1.php

Quezada, Noemí

1975 Amor y magia amorosa entre los aztecas. Supervivencia en el México colonial. México: UNAM.

Rosales, Adriana Leona

2006 "Género, sexualidad y cuerpo: mujeres indígenas y mestizas contemporáneas", en Género, cuerpo y sexualidad. Un estudio diacrónico desde la Antropología Social. Concepciones relativas al género, el cuerpo y la sexualidad en culturas mayas y nahuas prehispánicas y coloniales, $y$ en contextos étnicos minoritarios contemporáneos, pp. 180-295. Tesis de doctorado en Ciencias Antropológicas, Universidad Autónoma Metropolitana-Iztapalapa, México.

Ruz, Mario Humberto

2002 "Los mayas peninsulares", Los mayas peninsulares. Un perfil socioeconómico, pp. 7-45, M. H. Ruz (coord.). México: UNAM, IIFL, Cuadernos del Centro de Estudios Mayas.

Tarazona, Silvia

1991 La mujer mesoamericana. México: Planeta (Colección Mujeres en su Tiempo).

Velasco, Laura

2002 "El regreso de la comunidad étnica", El regreso de la comunidad: migración indígena y agentes étnicos. Los mixtecos en la frontera México-Estados Unidos, pp. 255-256. México: El Colegio de México / El Colegio de la Frontera Norte. 